\title{
EDITORIAL
}

\section{SENOLYTICS: THE MODERN SNAKE OIL?}

\author{
J.E. MORLEY \\ Corresponding author: John E. Morley, MB, BCh, Division of Geriatric Medicine, Saint Louis University School of Medicine, 1402 S. Grand Blvd., M238, St. Louis, MO 63104, \\ Email: john.morley@health.slu.edu
}

Key words: Senolytics, fountain of youth, senescence.

"What is the point of life if it ends in death"

John de Rivaz

Snake oil originally was a Chinese medication rich in omega-3 fatty acids which was made from the Chinese water snake. It was believed to decrease the pain of arthritis. The Hopi medicine men had used rattlesnake oil as an antiinflammatory. Rattlesnake oil has a lower concentration of omega-3 fatty acids. Towards the end of the 19th century Clark Stanley started selling rattlesnake oil as a cure for all diseases. The fact that this snake oil did not work led to the use of the term "snake oil" for substances of questionable efficacy that were sold with extravagant claims.

Long before "snake oil" human beings had sought the "fountain of youth" and immortality. The first documented quest for immortality was that of Gilgamesh. He went searching for a wise man, Utnapishtim ("The Faraway"), who sent him to find an herb at the bottom of the ocean which would endow him with longevity. Unfortunately, while Gilgamesh slept a snake ate the herb. Immediately after eating it, the snake shed its skin and thus was rejuvenated (1). Over the centuries numerous explorers and scientists have searched for the elusive "fountain of youth" without success.

In 1961, Leonard Hayflick demonstrated that as cells age they reach a stage where replication slows ("senescence") before they stop dividing (2). When young cells are injured they undergo apoptosis, display phosphatidylserine on their cell surface which attracts macrophages leading to their elimination from tissue. In contrast, senescence cells behave like 'zombies', not being appropriately cleared and become toxic to their environment. Senescent cells lose the ability to repair cell damage and they produce inflammatory cytokines, chemokines and protein degrading molecules (3). Thus, these cells develop a senescence associated secretory phenotype (SASP) (4).

In the latter part of the 20th century the focus for delaying aging and many chronic diseases was related to lifestyle factors, e.g., exercise, environmental pollution, dietary factors, smoking, infectious agents and reversing cellular toxicity e.g., DNA damage, oxidative stress, proteotoxic stress and telomere damage. In the 21st century the scientific focus has shifted to inhibition of SASP, enhancing survival pathways and increasing immune mediated clearance of senescent cells (5). A number of biochemical pathways have emerged as playing a key role in the aging process. These include insulin/insulinlike growth factor-1, target of rapamycin mechanistic mTOR, adenosine monophosphate activated protein kinase (AMPK) and the nicotinamide adenine dinucleotide (NAD+) - dependent sirtuin deacyclases (6). It is important to recognize that these pathways also play a key role in multiple other functions in the body, e.g., mTOR is essential for protein synthesis to develop muscle (7). These discoveries have led to scientists developing molecules to modulate these systems, some of which have been shown to extend lifespan in rodents $(8,9)$.

Senolytics are drugs that extend lifespan by having general positive effects throughout the body, rather than focusing on one disease. This has led some scientists to suggest that aging should be recognized as a disease, thus making senolytics into legitimate main stream drugs. The concept is that the focus of medical research should be on curing aging rather than increasing life- and health-span by focusing on individual diseases or even the geriatric syndromes. A major problem here is that showing in humans that a drug increases lifespan would theoretically need it to be administered from 50 or more years. To get around this, they suggest that showing an aging marker can be improved should be sufficient for regulatory agencies to approve it.

The senolytic combination of Dasatinib (atyrosinase kinase inhibitor) and Quercetin (targeting BCL-2 and insulin/IGF-1 systems) (DQ) causes apoptosis of senescent compared to nonsenescent cells in human tissue and extends lifespan in mice (10). A 3-week study in 14 subjects with idiopathic pulmonary fibrosis (IPF) showed some improvements in physical function but no improvement in lung function. The authors concluded that their study supports "feasibility and provides initial evidence that senolytics may alleviate physical dysfunction in IPF." This finding has received considerable publicity!

Sirtuins (nicotinamide adenine dinucleotide-dependent deacylases) were discovered in yeast in 1987 and demonstrated to play a role in extending yeast lifespan over 20 years ago $(11,12)$. The excitement around sirtiuns was increased when reservatrol, a compound in red wine purported to improve health in wine drinking French persons, was discovered to be a sirtuin activator (13). One study in humans showed that reservatrol increased muscle SIRT1, AMPK, mitochondrial activity and fatty acid oxidation (14). Other studies have not been as impressive (15). Alway et al (16) found that reservatrol 


\section{THE JOURNAL OF NUTRITION, HEALTH \& AGING@}

had a small effect on muscle fatigue and muscle peak torque and power. An apocryphal calculation based on the amount of reservatrol necessary to have positive effects in cells has suggested that a human would have to drink at least a case full of red wine a week to have the purported positive effects of reservatrol!

Another potential group of senolytic agents are stem cells. Osteoarthritis is a clear age-related disease and the internet is full of testimonials that stem cell injections into joints will reverse the aging damage. It is possible as processing of misenchymal and fat stem cells improve, this may be the case: Well conducted studies in humans demonstrate only minor effects of stem cells on osteoarthritis (17). There is growing evidence that mesenchymal stem cells can improve wound healing both by improving blood vessel growth into the wound and enhancing immune function (18).

Recently I visited a stem cell clinic in the beautiful mountains outside Chengdu in China. Here older persons can receive stem cells to reverse their aging! Stem cells have been studied as a therapy in heart disease. Results have been inconsistent and even with positive results the effects on heart function and cardiac remodeling has been small (19). In a small study of mesenchymal stem cells given to frail older persons, there was a decrease in $\mathrm{TNF} \alpha$ and a small increase in the 6-minute distance walked at 3 and 6 months after infusion (20). Overall, at present there appears little justification for using stem cells as senolytics but there is sufficient data to develop well designed clinical studies using appropriately prepared stem cell preparations. It should be recognized that stem cells generally work by releasing substances which rejuvenate the tissues around them and they do not produce a new set of youthful cells.

Type 2 diabetes mellitus is a form of accelerated aging (21). Metformin is the drug of choice for the treatment of diabetes and in those patients metformin may reduce cardiovascular disease (22-24). Metformin may also reduce mortality (25). A meta-analysis suggested that metformin may reduce both cancer incidence and death $(26,27)$. In addition, there is evidence that metformin may reduce dementia in older persons (28-30), but this is controversial (31). Metformin activates AMP-kinase, inhibits mTOR and reduces damage to DNA, all of which are positive effects of senolytics (32).

Mice without the Klotho gene have accelerated aging with increased atherosclerosis, thin bones and muscle atrophy (33). Klotho was named after one of the three fates in Greek mythology, who spun the thread of a person's life. When mice are genetically engineered to produce extra Klotho they live longer (34) and have improved memory (35). Klotho protein is induced by exercise (36) and increased levels regenerate atrophied muscle (37). In humans, besides exercise, insulin, PPAR gamma activators, ACE inhibitors and statins appear to increase Klotho (38). Statins increase survival by about $1 \%$ over 18 years $(39,40)$. The Klotho gene KL-VS is associated with longevity in humans (41).
CRISPR (clustered regularly interspace short palindromic repeats) recognizes specific DNA strands that then can be cleaved by the enzyme, Cas 9. CRISPR/Cas9 has been used to edit the LMNA mutation that produces progeria in mice (42). This approach of targeting lamin A and progerin increased lifespan by $25 \%$ in mice with the Hutchinson-Gilford progeria syndrome. Obviously CRISPR/Cas 9 can be used to inhibit SASP components in senescent cells using adenovirus as a vector.

Modulation of microRNAs represents another possible avenue to develop senolytics. For example, increased expression of miRNA-204 accelerates the development of osteoarthritis whereas inhibiting the expression of miRNA-204 leads to suppression of SASP, preventing the development of osteoarthritis (43).

\section{Examples of Failed Senolytics}

For many years antioxidant vitamins were considered an ideal product to extend life. This has led to USA sales of multivitamins amounting to $\$ 5.7$ billion in 2018 (ods.od.nih. gov/factsheets/mmvs-healthprofessional). A Cochrane metaanalysis has shown that antioxidant vitamins produce a small increase in mortality (44). Antioxidants decrease free radical production. These free radicals are necessary to kill infectious agents and cancer cells. A recent editorial in the Journal pointed out that vitamin D has been grossly oversold in the medical literature (45). In addition, high doses of vitamin D have a number of side effects.

\section{Conclusion}

While the basic science research on senolytics is very exciting, there is minimal evidence to support their use in humans. It is important to recognize that as we move into the era of Personalized (Precision) medicine it is quite likely that depending on a persons genetic background different senolytics may have different negative or positive effects in different individuals (46). Also, senolytics will be taken over many years and as such we have little idea of what long-term effects they may have, e.g., might they accelerate the development of some cancers?

At present sensible general advice to delay aging appears to be moderate exercise and ingesting a Mediterranean diet (47-49). The phenyls in extra virgin olive oil appear to protect against cardiovascular disease (50) and cognitive dysfunction (51-53). Including fish in the diet may also enhance longevity (54), but returning to the original snake oil the use of omega-3 fatty acids continues to be controversial (55).

It would appear that concentrating on improving the care of geriatric syndromes (56) is far more likely to improve outcomes compared to the focus on development of senolytics. Early recognition of frailty, using the FRAIL, and using a patient centered approach to treat the different components - fatigue, 


\section{SENOLYTICS: THE MODERN SNAKE OIL?}

sarcopenia, polypharmacy and weight loss appears reasonable (57). Similarly screening for sarcopenia with the SARC-F (58) and providing long-term exercise therapy compensated by the medical system makes for more sense than testosterone (59, $60)$ or antimyostatin drugs (61). While the biochemistry of senolytics is fascinating, it would seem that developing age friendly health systems with reimbursement for simple effective treatment approaches would seem a much more cost effective approach to extending a healthy life expectancy for older persons (62).

\section{Figure 1}

The Major Causes of Senescence and The Putative Senolytics to Prevent Them

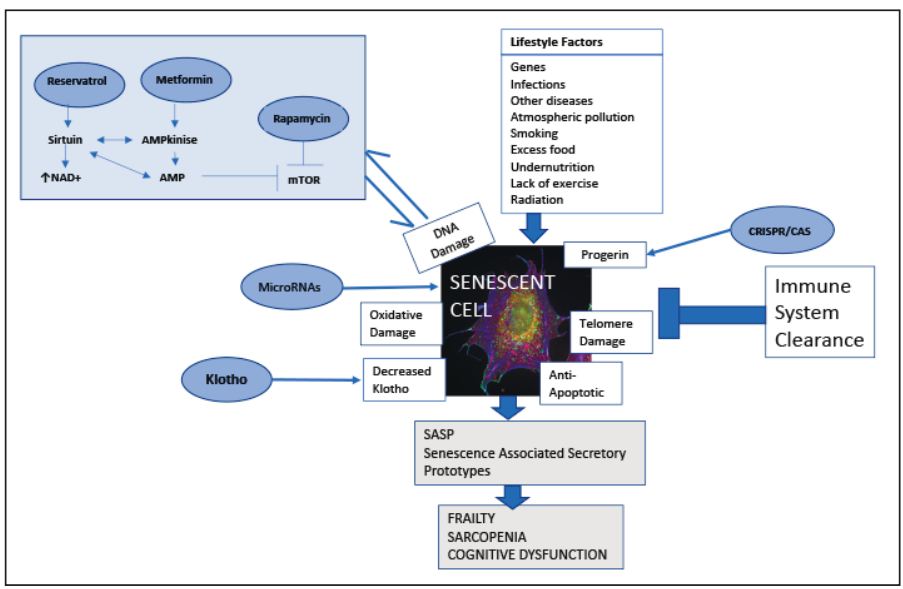

Disclosures: The authors declare there are no conflicts.

\section{References}

1. Morley JE. A brief history of geriatrics. J Gerontol A Biol Sci Med Sci 2004;59:1132-1152.

2. Hayflick L, Moorhead PS. The serial cultivation of human diploid cell strains. Exp Cell Res 1961;25:585-621.

3. Birch J, Passos JF. Targeting the SASP to combat ageing: Mitochondria as possible intracellular allies? Bioessays 2017;39: doi:10.1002/bies.201600235. Epub Feb 20.

4. $\mathrm{Li} \mathrm{Y,} \mathrm{Wu} \mathrm{Q,} \mathrm{Wang} \mathrm{Y,} \mathrm{Li} \mathrm{L,} \mathrm{Bu} \mathrm{H,} \mathrm{Bao} \mathrm{J.} \mathrm{Senescence} \mathrm{of} \mathrm{mesenchymal} \mathrm{stem} \mathrm{cells.} \mathrm{Int}$ J Mol Med 2017;39:775-782.

5. Childs BG, Durik M, Baker DJ, van Deursen JM. Cellular senescence in aging and age-related disease: From mechanisms to therapy. Nat Med 2015;21:1424-1435.

6. Bonkowski MS, Sinclair DA. Slowing ageing by design: The rise of NAD+ and sirtuin-activating compounds. Nat Rev Mol Cell Biol 2016;17:679-690.

7. Morley JE. The mTOR conundrum: Essential for muscle function, but dangerous for survival. J Am Med Dir Assoc 2016;17:963-966.

8. Bitto A, Ito TK, Pineda VV, et al. Transient rapamycin treatment can increase lifespan and healthspan in middle-aged mice. Elife. 2016;Aug 23;5. Doi: 10.7554/ eLife. 16351

9. Pallauf K, Rimbach G, Rupp PM, Chin D, Wolf IM. Resveratrol and lifespan in model organisms. Curr Med Chem 2016;23:4639-4680.

10. Justice JN, Nambiar AM, Tchkonia T, et al. Senolytics in idiopathic pulmonary fibrosis: Results from a first-in-human, open-label, pilot study. Lancet Ebiomedicine 2019;40:554-563.

11. Wierman MB, Smith JS. Yeast sirtuins and the regulation of aging. FEMS Yeast Res 2014; $14: 73-88$

12. Moazed D, Johnson D. A deubiquitinating enzyme interacts with SIR4 and regulates silencing in S. cerevisiae. Cell 1996;86:667-677

13. Lopez-Miranda V, Soto-Montenegro ML, Vera G, et al. Resveratrol: A neuroprotective polyphenol in the Mediterranean diet. Rev Neurol 2012;54:349-356.

14. Lagouge M, Argmann C, Gerhart-Hines Z, et al. Resveratrol improves mitochondrial function and protects against metabolic disease by activating SIRT1 and PGC- $1 \alpha$. Cell 2006;127:1091-1093.

15. Williams CB, Hughes MC, Edgett BA, et al. An examination of resveratrol's mechanisms of action in human tissue: Impact of a single dose in vivo and dose responses in skeletal muscle ex vivo. PLoS One 2014;9:e102406. eCollection.

16. Alway SE, McCrory JL, Kearcher K, et al. Resveratrol enhances exercise-induced cellular and functional adaptations of skeletal muscle in older men and women. J Gerontol A Biol Sci Med Sci 2017;72:1595-1606.

17. Pas HI, Winters M, Haisma HJ, et al. Stem cell injections in knee osteoarthritis: A systematic review of the literature. Br J Sports Med 2017;51:1125-1133.

18. Nourian Dehkordi A, Mirahmadi Babaheydari F, Chehelgerdi M, Raeisi Dehkordi S. Skin tissue engineering; Wound healing based on stem-cell-based therapeutic strategies. Stem Cell Res Ther 2019;10:111

19. Fisher SA, Doree C, Mathur A, et al. Stem cell therapy for chronic ischaemic heart disease and congestive heart failure. Cochrane Database Syst Rev 2016;Dec 24;12:CD007888. Doi: 10.1002/14651858.CD007888.pub3.

20. Thompkins BA, DiFede DL, Khan A, et al. Alogeneic mesenchymal stem cells ameliorate aging frailty: A phase II randomized, double-blind, placebo-controlled clinical trial. J Gerontol A Biol Sci Med Sci 2017;72:1513-1522.

21. Morley JE. Diabetes and aging: Epidemiologic overview. Clin Geriatr Med 2008;24:395-405.

22. Griffin SJ, Leaver JK, Irving GJ. Impact of metformin on cardiovascular disease: A meta-analysis of randomized trials among people with type 2 diabetes. Diabetologia. 2017;60:1620-1629.

23. Anfossi G, Russo I, Bonomo K, Trovati M. The cardiovascular effects of metformin: Further reasons to consider an old drug as cornerstone in the therapy of type 2 diabetes mellitus. Curr Vasc Pharmacol 2010;8:327-337.

24. Roumie CL, Hung AM, Greevy RA, et al. Comparative effectiveness of sulfonylurea and metformin monotherapy on cardiovascular events in type 2 diabetes mellitus: A cohort study. Ann Intern Med 2012;157:691-610.

25. Campbell JM, Bellman SM, Stephenson MD, Lisy K. Metformin reduces all-cause mortality and diseases of ageing independent of its effect on diabetes control: A systematic review and meta-analysis. Ageing Res Rev 2017;40:31-44.

26. Perez-Lopez FR, Pasupuleti V, Gianuzzi X, et al. Systematic review and metaanalysis of the effect of metformin treatment on overall mortality rates in women with endometrial cancer and type 2 diabetes mellitus.

27. Thakkar B, Aronis KN, Vamvini MT, et al. Metformin and sulfonylureas in relation to cancer risk in type II diabetes patients: meta-analysis using primary data of published studies. Metabolism 2013;62:922-934.

28. Orkaby AR, Cho K, Cormack J, et al. Metformin vs sulfonylurea use and risk of dementia in US veterans aged $>65$ year with diabetes. Neurology 2017;89:1877-1885.

29. Ng TP, Feng L, Yap KB, et al. Long-term metformin usage and cognitive function among older adults with diabetes. J Alzheimers Dis 2014;41:61-68.

30. Campbell JM, Stephenson MD, de Courten B, et al. Metformin use associated with reduced risk of dementia in patients with diabetes: A systematic review and metaanalysis. J Alzheimers Dis 2018;65:1225-1236.

31. Weinstein G, David-Plourde KL, Conner S, et al. Association of metformin, sulfonylurea and insulin use with brain structure and function and risk of dementia and Alzheimer's disease: Pooled analysis from 5 cohorts. PLoS One 2019;14:e212293.

32. Li M, Li X, Zhang H, Lu Y. Molecular mechanisms of metformin for diabetes and cancer treatment. Front Physiol 2018;9:1039. eCollection. Doi: 10.3389/ fphys.2018.01039.

33. Cheikhi A, Barchowsky A, Sahu A, et al. Klotho: An elephant in aging research. J Gerontol A Biol Sci Med Sci 2019;7 doi:10.1093gerona/glz061 [Epub ahead of print].

34. Dërmaku-Sopjani M, Kolgeci S, Abazi S, Sopjani M. Significance of the anti-aging protein Klotho. Mol Membr Biol 2013;30:369-385.

35. Dubal DB, Yokoyama JS, Zhu L, et al. Life extension factor klotho enhances cognition. Cell Rep 2014;7:1065-1076.

36. Tan WJ, Chu MM, Toussaint ND, et al. High-Intensity physical exercise increases serum $\alpha$-klotho levels in healthy volunteers. J Circ Biomark 2018;7:1849454418794582. Ecollection.

37. Amaro-Gahete FJ, de-la-O A, Jurado-Fasoli L, et al. Role of exercise on S-Klotho protein regulation: A systematic review. Curr Aging Sci 2018;11:100-107.

38. Narumiya H, Sasaki S, Kuwahara N, et al. HMG-CoA reductase inhibitors up-regulate anti-aging klotho mRNA via RhoA inactivation in IMCD3 cells. Cardiovasc Res 2004;64:331-336.

39. Nunes JP. Statins in primary prevention: Impact on mortality: A meta-analysis study Minerva Cardioangiol 2017;65:531-538.

40. Hunt D, Young P, Simes J, et al. Benefits of pravastatin on cardiovascular event and mortality in older patients with coronary heart disease are equal to or exceed those seen in younger patients: Results from the LIPID panel. Ann Intern Med 2001;134:931-940.

41. Revelas M, Thalamuthu A, Oldmeadow C, et al. Review and meta-analysis of genetic polymorphisms associated with exceptional human longevity. Mech Ageing Dev 2018;175:24-34.

42. Santiago-Fernandez O, Osorio FG, Quesada V, et al. Development of a CRISPR/ Cas9-based therapy for Hutchinson-Gilford progeria syndrome. Nat Med 2019;25:423-426.

43. Kang D Shin J, Cho Y, et al. Stress-activated miR-204 governs senescent phenotypes of chondrocytes to promote osteoarthritis development. Sci Transl Med 


\section{THE JOURNAL OF NUTRITION, HEALTH \& AGINGC}

2019:11(486). Doi:10.1126/scitranslmed aar6659.

44. Bjelakovic G, Nikolova D, Gluud LL, et al. Antioxidant supplements for prevention of mortality in healthy participants and patients with various diseases. Cochrane Database Syst Rev 2012 Mar 14;(30:CD007176.

45. Morley JE. Editorial: Vitamin D: Does the emperor have no clothes? J Nutr Health Aging 2019;23:316-317.

46. Morley JE, Anker SD. Myopenia and precision (P4) medicine. J Cachexia Sarcopenia Muscle 2017;8:857-863.

47. Becerra-Tomas N, Blanco Mejia S, Viguiliouk E, et al. Mediterranean diet, cardiovascular disease and mortality in diabetes: A systematic review and metaanalysis of prospective cohort studies and randomized clinical trials. Crit Rev Food Sci Nutr 2019;24:1-21.

48. de Souto Barreto P, Rolland Y, Vellas B, Maltais M. Association of long-term exercise training with risk of falls, fractures, hospitalizations, and mortality in older adults: A systematic review and meta-analysis. JAMA Intern Med 2018;Dec 28 doi:10.1001/jamainternmed.2018.5406 [Epub ahead of print].

49. Martinez-Gonzalez MA, Gea A, Ruiz-Canela M. The Mediterranean diet and cardiovascular health. Circ Res 2019;124:779-798.

50. Tsartsou E, Proutsos N, Castanas E, Kampa M. Network meta-analysis of metabolic effects of olive-oil in humans shows the importance of olive oil consumption with moderate polyphenol levels as part of the Mediterranean diet. Front Nutr 2019;6:6 eCollection.

51. Singh B, Parsaik AK, Mielke MM, et al. Association of Mediterranean diet with mild cognitive impairment and Alzheimer's disease: A systematic review and metaanalysis. J Alzheimers Dis 2014;39:271-282.

52. Martinez-Lapiscina EH, Clavero P, Toledo E, et al. Virgin olive oil supplementation and long-term cognition: The PREDIMED-NAVARRA randomized, trial. J Nutr Health Aging 2013;17:544-552.
53. Farr SA, Price TO, Dominguez LJ, et al. Extra virgin olive oil improves learning and memory in SAMP8 mice. J Alzheimers Dis 2012;28:81-92.

54. Jayedi A, Shab-Bidar S, Eimeri S, Djafarian K. Fish consumption and risk of allcause and cardiovascular mortality: A dose-response meta-analysis of prospective observational studies. Public Health Nutr 2018;21:1297-1306.

55. Abdelhamid AS, Martin N, Bridges C, et al. Polyunsaturated fatty acids for the primary and secondary prevention of cardiovascular disease. Cochrane Database Syst Rev 2018;7:CD012345.

56. Morley JE. The new geriatric giants. Clin Geriatr Med 2017;33:xi-xii.

57. Morley JE, Little MO, Berg-Weger M. Rapid geriatric assessment: A tool for primary care physicians. J Am Med Dir Assoc 2017;18:195-199.

58. Dent E, Morley JE, Cruz-Jentoft AJ, et al. International clinical practice guidelines for sarcopenia (ICFSR): Screening, diagnosis and management. J Nutr Health Aging 2018;22:1148-1161.

59. Bhasin S, Ellenberg SS, Storer TW, et al. Effect of testosterone replacement on measures of mobility in older men with mobility limitation and low testosterone concentrations: Secondary analyses of the testosterone trials. Cancer Diabetes Endocrinol 2018;6:879-890.

60. Albert SG, Morley JE. Testosterone therapy, association with age, initiation and mode of therapy with cardiovascular events: A systematic review. Clin Endocrinol (Oxf). 2016;85:436-443.

61. McKee A, Morley JE, Matsumoto AM, Vinik A. Sarcopenia: An endocrine disorder? Endocr Pract 2017;23:1140-1149.

62. Sanford AM, Berg-Weger M, Ludy J, Morley JE. Editorial: Aging friendly health systems. J Nutr Health Aging 2019;23:119-121. 